\title{
Use of interactive lecture demonstrations: A ten year study
}

\author{
Manjula D. Sharma, Ian D. Johnston, Helen Johnston, Kevin Varvell, Gordon Robertson, Andrew Hopkins, Chris Stewart, \\ Ian Cooper, and Ronald Thornton* \\ School of Physics, University of Sydney, New South Wales 2006, Australia
}

(Received 1 June 2010; published 8 October 2010)

\begin{abstract}
The widely held constructivist view of learning advocates student engagement via interactivity. Within the physics education research community, several specific interactive strategies have been developed to enhance conceptual understanding. One such strategy, the Interactive Lecture Demonstration (ILD) is designed for large lecture classes and, if measured using specific conceptual surveys, is purported to provide learning gains of up to $80 \%$. This paper reports on learning gains for two different Projects over ten years. In Project 1 , the ILDs were implemented from 1999 to 2001 with students who had successfully completed senior high school physics. The learning gains for students not exposed to the ILDs were in the range $13 \%$ to $16 \%$ while those for students exposed to the ILDs was 31\% to 50\%. In Project 2, the ILDs were implemented from 2007 to 2009 with students who had not studied senior high school physics. Since the use of ILDs in Project 1 had produced positive results, ethical considerations dictated that all students be exposed to ILDs. The learning gains were from $28 \%$ to $42 \%$. On the one hand it is pleasing to note that there is an increase in learning gains, yet on the other, we note that the gains are nowhere near the claimed $80 \%$. This paper also reports on teacher experiences of using the ILDs, in Project 2.
\end{abstract}

DOI: 10.1103/PhysRevSTPER.6.020119

PACS number(s): 01.40.Fk, 01.40.Di, 01.40.gb

\section{INTRODUCTION}

A great deal of the physics education research of the past 30 or so years has been driven by the belief, supported by a substantial body of evidence, that traditional lecturing is not an effective way of producing learning or understanding in students [1]. In the widely held constructivist view of learning, this is attributed to the idea that students enter physics classes with a set of concepts of how the physical world works, which are often at odds with the canonical scientific understanding. These concepts are very firmly held and often extremely difficult to change just by the students being told differently $[2,3]$.

The combined research findings of many diverse groups have identified some very common misconceptions, and this has led to the construction of standardized diagnostic tests, designed to identify how prevalent and how firmly held are these misconceptions by various groups of students $[4,5]$. This, in turn, has prompted the development of targeted teaching strategies which concentrate on improving student understanding by eradicating the identified misconceptions $[6,7]$. Most of these strategies have been evaluated for teaching and learning effectiveness, by independent teachers as well as by their authors. A compilation of many such evaluations has been made [8], with which it was possible to compare the increase in conceptual understanding in classes taught by the new strategies (which are generally described as interactive engagement) with classes taught by traditional, "chalk-and-talk" (noninteractive) methods [9]. The bottomline conclusion drawn from this comparison was that, in nearly every group of students studied, interactive strategies produce considerably more gain in conceptual understanding than traditional teaching.

\footnotetext{
*Present address: Center for Science and Mathematics Teaching,
} Tufts University, Medford MA 02155 USA.
If these results are taken at face value, the questions can be asked: Why do not more (all?) physics courses use interactive engagement strategies? Why is traditional, chalk-andtalk teaching still the norm? At least one plausible answer springs to mind. In a university with large enrolments in first year physics courses, like ours, students are often streamed according to high school exam performance, and courses are mounted in parallel sessions, as dictated by the timetable. Syllabuses are laid down by departmental committees, constrained by the state-wide high school syllabus at one end, and the needs of higher-level courses at the other. To make a permanent, major change in teaching would be no mean undertaking. All lecturers involved, now and after any reallocation of teaching duties, must be willing to change their teaching, and ethical considerations would demand that changes be consistent across parallel streams. To justify such an upheaval, there would have to be some kind of guarantee that the new teaching strategy would indeed produce sufficiently large, on-going increases in conceptual understanding, under the conditions that apply in ordinary universities.

At the University of Sydney, some 10 years ago, it was decided to investigate whether there was indeed enough relevant evidence that could justify such an undertaking. Working with the introductory physics classes, it was proposed to determine the increase in conceptual understanding made by one particular teaching strategy, the so-called Interactive Lecture Demonstration (ILD) $[10,11]$, as measured by one particular conceptual survey instrument, the Force and Motion Concept Evaluation, (FMCE) [12-15]. The aim was to see whether the increase in conceptual understanding (if any) supported the claims made in the literature, especially under very different conditions.

There were three overall research questions:

(1) Can a substantial gain in conceptual understanding be expected if introductory physics courses are taught using ILDs, over and above traditional methods, for different teachers, student levels and years? 

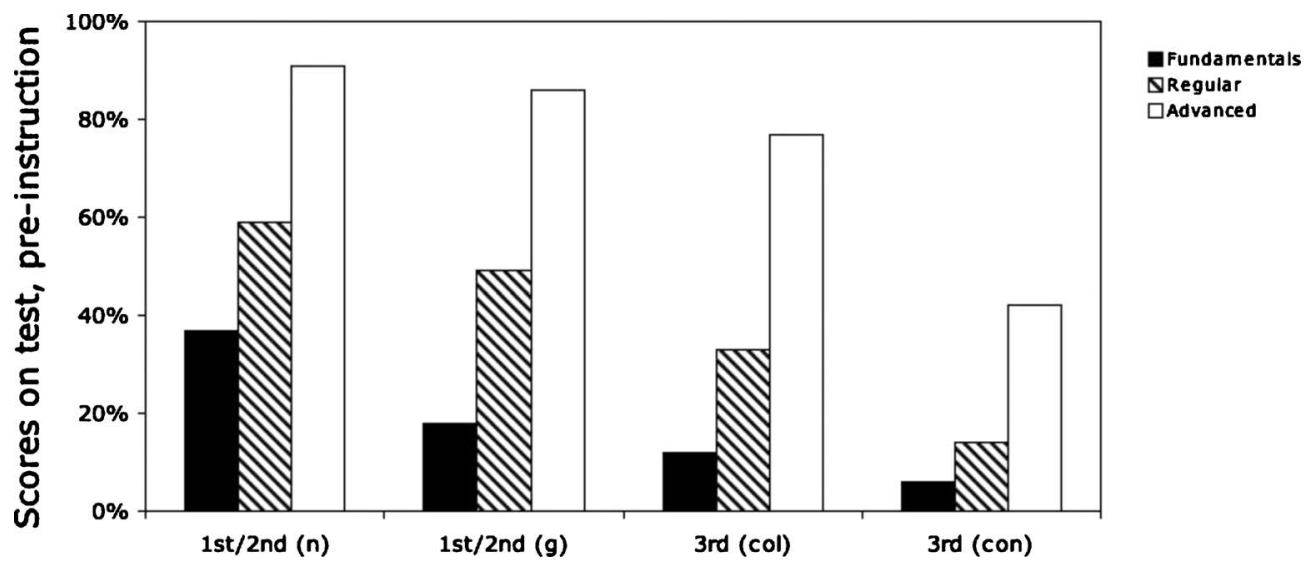

FIG. 1. Preinstruction scores according to the topics covered by the test for the Fundamentals, Regular, and Advanced students in 1995.

(2) How does the average gain in conceptual understanding measured for introductory physics classes at the University of Sydney using ILDs compare with results quoted for other universities?

(3) How do participating teachers respond to the use of ILDs?

\section{EVALUATION OF ILDS AT THE UNIVERSITY OF SYDNEY}

In the decade 1999-2009, several semi-independent "experiments" were undertaken at the University of Sydney, working with the introductory physics classes. The aim was to address these research questions, by subdividing the overall investigation into four self-contained projects. These aimed to determine

(i) the level of conceptual understanding of students entering the introductory physics courses in this institution;

(ii) the efficacy of the standard first year physics teaching in this institution;

(iii) the efficacy of ILDs in improving first year physics teaching in this institution; and

(iv) the consistency of such improvement across different instructors and years.

First year physics teaching at the University of Sydney is characterized by the following features:

(i) The total number of students is $\sim 900$, all of whom, if they chose, could major in physics.

(ii) These students are streamed into 3 levels: The first two, Advanced (1 class), and Regular (3 classes) are for students who have done senior high school physics and the streaming is done in decreasing order of university entry mark (based on a state-wide examination in the final year of high school studies). The Fundamentals stream is for students who have not done senior high school physics, resulting in an essentially bimodal distribution: about half of the students have a university entry mark similar to that of the Regular stream, and the other half similar to the Advanced.

(iii) Classes are taught by different lecturers in parallel, in relatively short blocks called "modules" of $\sim 4$ or 5 weeks each. (iv) The "material to be covered" is rigorously prescribed by a departmental syllabus committee. Individual lecturers have very limited freedom to change anything.

(v) By and large teaching tends to be mostly traditional "chalk (or PowerPoint) and talk" to large classes of 100+.

The diagnostic test chosen was the Force and Motion Concept Evaluation (FMCE) [12-15]. This test addresses the subject of Newtonian dynamics as taught at tertiary introductory level. It consists of 47 elementary, multiple choice questions to be answered in $\sim 30 \mathrm{~min}$. The questions are grouped into ten related concepts: velocity, acceleration, first law, etc.; and the test is scored using a rubric, in agreement with guidelines in the original ILD paper [12]. The energy questions were not included.

The teaching intervention chosen is known as Interactive Lecture Demonstrations (ILD) $[10,11,16]$. These involve doing simple experiments involving, for example, carts running along tracks, and objects thrown into the air. They employ computers and sensors to log and display data in various representations. They rely on carefully controlled, prechoreographed teacher-class interactions, with students making and discussing predictions that are then tested; and all of this is done within an otherwise ordinary lecture. The original authors of this intervention claim very substantial gains in student learning [12].

\section{PROJECT 1: METHODOLOGY}

The immediate question that had to be addressed was: with which stream, Fundamental, Regular, or Advanced, would it be most useful to test the ILDs? Some years previously, in 1995, when this project was first mooted, all introductory students were given the FMCE in their first physics lecture of the year. Scores for students in each stream were calculated, and subdivided into four broad groupings according to the topics covered by the various questions on the test-Newton's first and second laws, motion under gravity, the third law relating to collisions, and the third law relating to contact forces. The results are shown in Fig. 1.

It is clear from this data that the level of understanding of students on entry varies enormously, over the three streams 
and over the physics involved. Compared with entry scores reported elsewhere [12], the scores for the Advanced stream, while not uniform over all topics, are very high. At the other end, scores for the Fundamental students are quite low, as would be expected with students who did not study physics in the last two years of high school.

On the basis of these results, there hardly seemed enough room for great improvement for students in the Advanced stream. Of the other two, students in the Regular stream are known to be more likely to study physics at higher levels. It was felt that they would benefit more in the long run if more attention was paid to improving their level of conceptual understanding at introductory level. Therefore, for Project 1, the first year physics students were divided thus: one Regular class (130 students) was chosen to be taught using ILDs (the "experimental" class). The Advanced stream and the other two Regular streams (320 students) acted as controls. Fundamentals students were not included.

The lecture module chosen was Mechanics, the syllabus defined by relevant section of the text book, Halliday, Resnick, and Walker, chapters 1-12 [17]. All classes were given $151 \mathrm{~h}$ lectures, spread over 5 weeks. For the experimental class, four of the $1 \mathrm{~h}$ sessions were designed around the first four ILD experiences, as laid down in the documentary material provided with the ILD package. All students were asked to complete the conceptual test (the FMCE) before teaching started (the pretest) and again a few weeks after teaching in that module was finished (the post-test).

The second experiment, carried out in 2000, was a repeat of the first. The class numbers were roughly the same, and the same logistics were followed. In particular, the lecturer had not changed. For various unavoidable reasons, only the three Regular streams were given the pretest. All three Regular streams and the one Advanced stream were given the post-test (it was given at the same time as a compulsory midsemester laboratory exam but the marks were not included in the end of semester assessment).

The third experiment was done in 2001. Again it was as the first, but a different lecturer took over the experimental class. Table I summaries the various sources of data used in Project 1 . The student numbers reported are for students who have completed all ILDs, and pre- and post-tests, in other words a matched data set.

\section{PROJECT 1: RESULTS}

\section{A. Level of conceptual understanding of students on entry}

The pretest scores for all Regular students (in both the experimental and control groups), for the three years 19992001, are plotted in Fig. 2. In this plot scores are combined over the four topic areas that the FMCE covers, weighted in accordance with guidelines in the original ILD paper. For comparison the 1995 data is included, as is the initial entry data for a discontinued run in 2002 .

The main observation that can be made from Fig. 2 is that the average scores before instruction do not vary drastically. Thus it can be assumed for the rest of this investigation, that the level of understanding of Regular students on entry can
TABLE I. Various sources of the data used in the analysis of Project I.

\begin{tabular}{|c|c|}
\hline Year & Data collected \\
\hline 1995 & $\begin{array}{c}278 \text { Regular; traditional teaching; pre- and } \\
\text { postresults } 50 \text { Advanced; traditional teaching; } \\
\text { pre- and postresults }\end{array}$ \\
\hline 1999 & $\begin{array}{l}81 \text { Regular; ILDs; lecturer 1; pre- and postresults } \\
104 \text { Regular; traditional teaching; } \\
\text { pre- and postresults } 68 \text { Advanced; } \\
\text { traditional teaching; pre- and postresults }\end{array}$ \\
\hline 2000 & $\begin{array}{c}79 \text { Regular; ILDs; lecturer 1; pre- and postresults } \\
112 \text { Regular; traditional teaching; } \\
\text { pre- and postresults }\end{array}$ \\
\hline 2001 & $\begin{array}{l}80 \text { Regular; ILDs; lecturer 2; pre- and postresults } \\
298 \text { Regular; traditional teaching; } \\
\text { pre- and postresults }\end{array}$ \\
\hline 2002 & 349 Regular; preresults only \\
\hline
\end{tabular}

be taken as close enough to uniform to make comparisons meaningful.

\section{B. Efficacy of traditional first year physics teaching}

A widely agreed-on way to "measure" the increase in conceptual understanding brought about by a period of teaching is to compare an average pretest score for the class, using the conceptual survey, before instruction starts, and a post-test score, using the same survey, after instruction has finished. The comparison is most often done by calculating the average normalized gain, defined by

$$
\sigma=\frac{\text { post-test }- \text { pretest }}{100-\text { pretest }} \times 100,
$$

where all quantities are expressed as percentages.

Based on this measure, Table II shows a comparison of preinstruction to postinstruction scores for traditionally taught classes at Sydney in 1995, 1999-2001. It shows the actual pre- and post-test scores and the average normalized gains. Only the scores of Regular students in the control classes are included.

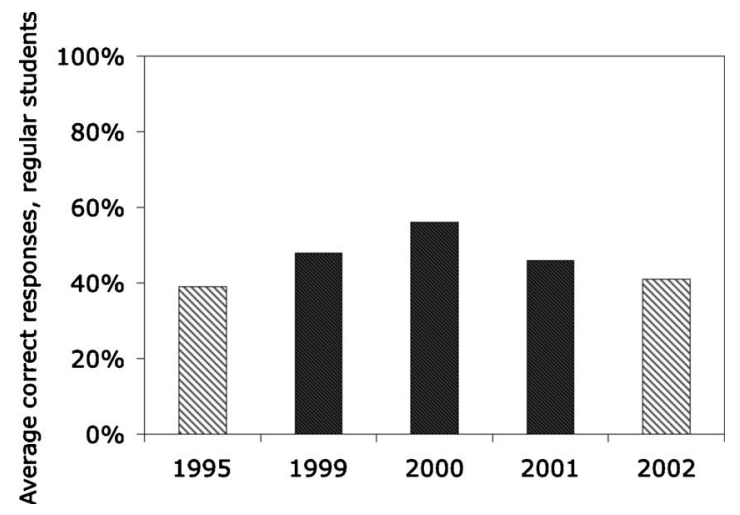

FIG. 2. Average correct responses for the Regular students, preinstruction, in 1995, and from 1999 to 2002. 
TABLE II. Post-test gains for traditional teaching in 1995, and from 1999 to 2001.

\begin{tabular}{ccccc}
\hline \hline Year & Number & $\begin{array}{c}\text { Pretest } \\
(\%)\end{array}$ & $\begin{array}{c}\text { Post-test } \\
(\%)\end{array}$ & $\begin{array}{c}\text { Normalized gains } \\
(\%)\end{array}$ \\
\hline 1995 & 278 & 38 & 49.5 & 19 \\
1999 & 104 & 48 & 55 & 16 \\
2000 & 112 & 55 & 60 & 13 \\
2001 & 298 & 45 & 54 & 16 \\
\hline \hline
\end{tabular}

The most straightforward observation to be made is that all normalized gains are quite low, less than 20\%. Students who scored between $40 \%$ and $55 \%$ before entering the class, scored between 50 and $60 \%$ after receiving a 15-lecture course in Newtonian mechanics. This figure is the same kind of figure that has been reported many times in the literature, over many different teaching institutions and years $[9,12]$. It strongly supports the widely held belief that traditional teaching is not particularly good at increasing conceptual understanding.

\section{Efficacy of ILDs in improving first year physics teaching}

The experimental classes did better than the controls. In somewhat greater detail, Fig. 3 shows the actual (average) weighted correct scores for the three classes of Regular students who had been exposed to ILD teaching for 1999-2001. The results are conventionally subdivided into ten different categories of subject matter, in order to allow teachers to know just where the main problems are to be found.

Comparison with the results of non-ILD teaching can be seen in terms of average normalized gains. See Table III.

The following observations can be made immediately:

(i) The gains with ILD teaching were significantly larger than for traditional teaching. This supports some of the claims made by proponents of the use of ILDs. However, it needs to be stressed immediately that they were not nearly as great as the figures of $\sim 80 \%$ claimed elsewhere [12].

(ii) The gains vary from year to year. The most obvious factor seemed to be the experience of the lecturer. Lecturer 1 used ILDs for the first time in 1999, and for the second time in 2000. The gains he achieved were significantly greater in 2000 than in 1999. This could be attributed to technical problems with the equipment, or how it was handled, which are always likely to be more important the first time any course is given. This is particularly relevant here because the ILDs are very heavily equipment dependent.

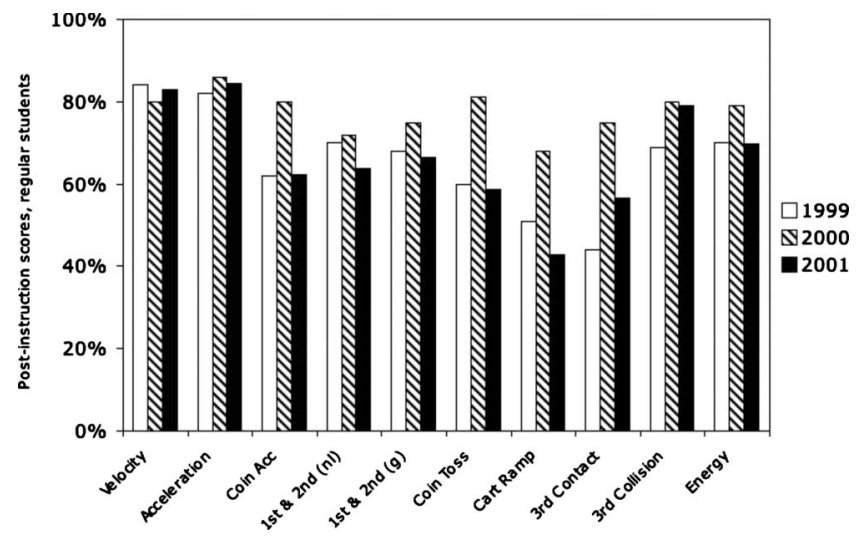

FIG. 3. Postinstruction scores for Regular students, exposed to ILD methods of instruction, 1999-2001.

(iii) It is tempting to propose a hypothesis for further exploration, that experience helps the instructor do what is required confidently and competently.

\section{Comparison with similar published studies}

An influential classification scheme was developed by Hake [9] to differentiate between traditional-teaching methods and interactive engagement strategies. This scheme represents the average increase in conceptual understanding for any particular class of students as a point on a graph of gain vs preinstruction score. He identified several regions of the graph in which representative points were to be found, corresponding to high gain, medium gain and low gain, respectively. His finding was that, of 62 introductory physics courses within the U.S., those classes which were taught by traditional methods tended to fall into the low-medium regions; while those taught by interactive engagement methods tended to fall into the medium-high regions.

It is useful to try to use this plot to compare our findings with those of other institutions. But it should be borne in mind that this method of comparing results was designed for use with another conceptual survey, the Force Concept Inventory (FCI) [18], and not the FMCE. Nevertheless some work has been done on calibrating the two against one another [15] and it is probably reasonable to assume that the two measures are correlated and give roughly comparable measures for "conceptual understanding."

Figure 4 shows Hake's original plot, reproduced here with permission, and a similar graph indicating where the values of gain of the seven student groups we determined above

TABLE III. Average normalized gains for ILD teaching, compared with those of traditional teaching, 1999-2001.

\begin{tabular}{cccccc}
\hline \hline Year & Number of students & $\begin{array}{c}\text { Preinstruction } \\
\text { (ILD) }(\%)\end{array}$ & $\begin{array}{c}\text { Postinstruction } \\
\text { (ILD) }(\%)\end{array}$ & $\begin{array}{c}\text { Norm. gains } \\
\text { (ILD) }(\%)\end{array}$ & $\begin{array}{c}\text { Norm. gains } \\
\text { (non-ILD) (\%) }\end{array}$ \\
\hline 1999 & 81 & 51 & 66 & $\mathbf{3 1}$ & $\mathbf{1 6}$ \\
2000 & 79 & 58 & 79 & $\mathbf{5 0}$ & $\mathbf{1 3}$ \\
2001 & 80 & 47 & 70 & $\mathbf{4 3}$ & $\mathbf{1 6}$ \\
\hline \hline
\end{tabular}



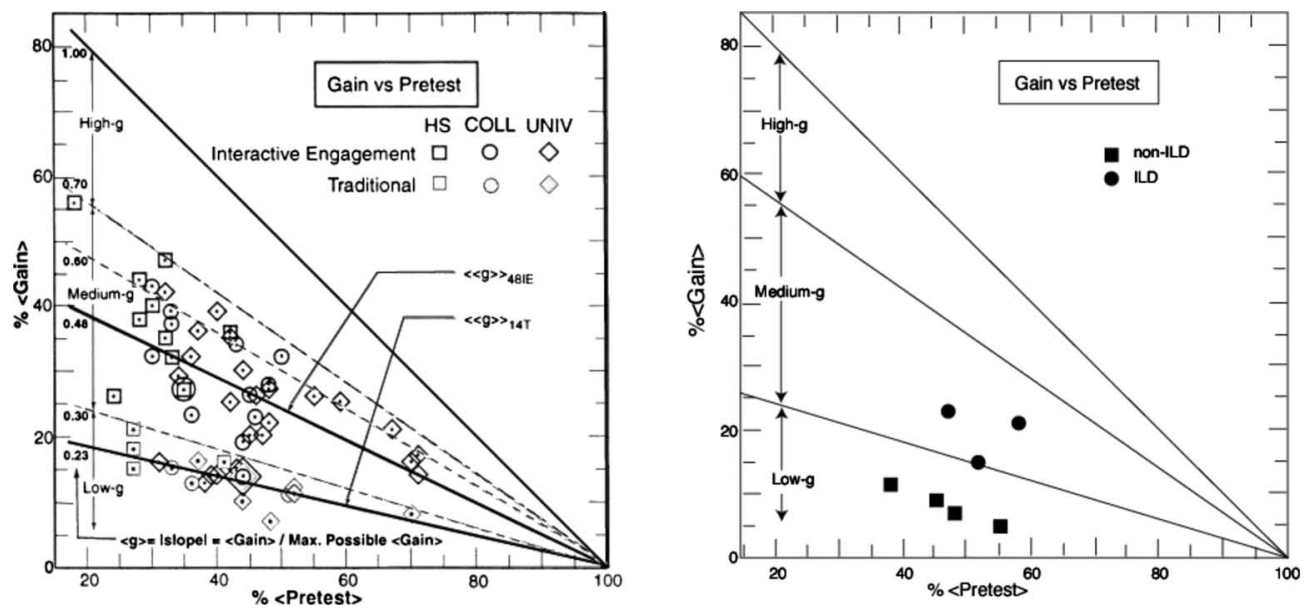

FIG. 4. Raw gains vs preinstruction score, (a) from Hake [9] measured by the FCI, and (b) for the current project, measured by the FMCE.

would be located. (Note: raw gains are plotted, not normalized gains.)

It will be observed that the ILD and non-ILD points fall in different areas of the graph, but even so, none of the gains are what might be thought of as high.

\section{PROJECT 2: USING FUNDAMENTALS STUDENTS}

\section{A. Logistics}

Subsequent to the completion of the first project, much thought was given to possible reasons why the gains achieved, while very reasonable, were not as high as expected or hoped. Discussions with the original author of the ILDs, who viewed videotapes taken during the trials, suggested that perhaps the classroom demonstrations were not done "properly." In particular it could be argued that the lecturers talked too much, instead of allowing the students to do all the work.

A more quantifiable suggestion was that, because the pretest scores for the Regular students were very high to start with, there was not enough room for them to improve their scores before reaching a ceiling. That at least could be tested, by working with students whose preinstruction scores were lower than those of the Regulars. Hence it was decided to repeat the experiment using students from the Fundamentals class. This was done in the period 2007-2009.

A number of considerations caused the logistics of the second project to be different from the earlier one. First, the content of the lecture courses had been changed to reflect changes in the state-wide high school syllabus, made in 2001. As a result, the Fundamentals class now receives, in semester 1, a 4-week module called "Language of Physics," followed by a 5-week module "Mechanics." It was decided to spread the five lecture slots involving ILDs over these two modules-two during "Language" and three during "Mechanics." That meant that three lecturers were involved in the project in all three years (denoted as lecturers 3-5); and one lecturer (6) was replaced (by 7) for years 2008-9.

Second, because the disruptions to the teaching syllabus were greater than before, ethical considerations were more important. It was felt that both the parallel Fundamentals classes must have the same teaching experience. So it was no longer possible to use one of those classes as a control. Therefore the research question for Project 2 no longer involved comparing ILDs with traditional teaching directly. Rather interest had shifted to comparing ILD teaching over different lecturers, different years and different level and backgrounds of students.

Lastly, there was the question of what the students get out of participating in this project. In 2007-8, student participation was completely voluntary. Attendance at lectures was not compulsory, and neither the pre- nor the post-test were awarded any marks toward the end-of-semester assessment. As a consequence the number of returns was low. In 2009, the ILD sessions were integrated into the overall assessment-attendance at the ILD sessions was given a (small) participation mark. The pre- and post-tests were still not formally assessed (Note that in our context, the students respond well without the incentive of marks).

The data collected for this project are shown in Table IV. The student numbers reported are for students who have completed all ILDs, as well as pre- and post-tests, in other words a matched data set. The Fundamentals class size is around 220, this means that the participation rate in 2009 was $72 \%$. Notice that data from the 1995 survey, although ostensibly available, was not used, mainly because it was felt that the time gap, and the change in high school syllabus would make comparisons of doubtful usefulness.

TABLE IV. Various sources of the data used in the analysis of Project 2.

\begin{tabular}{|c|c|}
\hline Year & Data collected \\
\hline 2007 & $\begin{array}{l}90 \text { Fundamentals; ILDs; lecturers } 3,4,5,6 \text {; } \\
\text { pre and post results }\end{array}$ \\
\hline 2008 & $\begin{array}{l}115 \text { Fundamentals; ILDs; lecturers 3, 4, 5, 7; } \\
\text { pre and post results }\end{array}$ \\
\hline 2009 & $\begin{array}{c}158 \text { Fundamentals; ILDs; lecturers } 3,4,5,7 \text {; } \\
\text { pre and post results }\end{array}$ \\
\hline
\end{tabular}




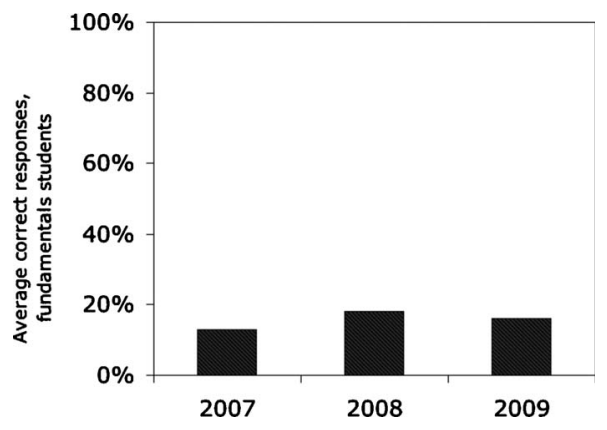

FIG. 5. Average correct responses for Fundamentals students preinstruction from 2007 to 2009.

\section{B. Level of conceptual understanding of students on entry}

The pretest scores for all Fundamentals students for the three years 2007-2009, are plotted in Fig. 5. In this plot scores are combined over the four topic areas that the FMCE covers.

Again the main observation that can be made from this figure is that the differences between average scores before instruction are not significant, and it can be assumed they are close enough to uniform to make comparisons meaningful.

\section{Efficacy of ILDs in teaching to Fundamentals students}

We present, in Fig. 6, the actual (average) final scores for the two classes of Fundamentals students who had been exposed to ILD teaching for each of 2007-9. Again, the results are conventionally subdivided into ten different categories of subject matter. A comparison of the scores for Regular students with those for Fundamentals can be made by comparing Figs. 3 and 6.

Comparison of the results for the three years is best shown in terms of average normalized gains. See Table V. Note that there were no traditional-teaching results with which to compare these. But comparison with the Regular students can be made by comparing Tables III and V.

\section{Results from Project 2}

Again a few observations can be made immediately. Students' scores did improve, and if this improvement was not as great as predicted by others, nonetheless it was a quite reasonable improvement. Unfortunately we do not have nonILD scores with which to compare these results. As men-

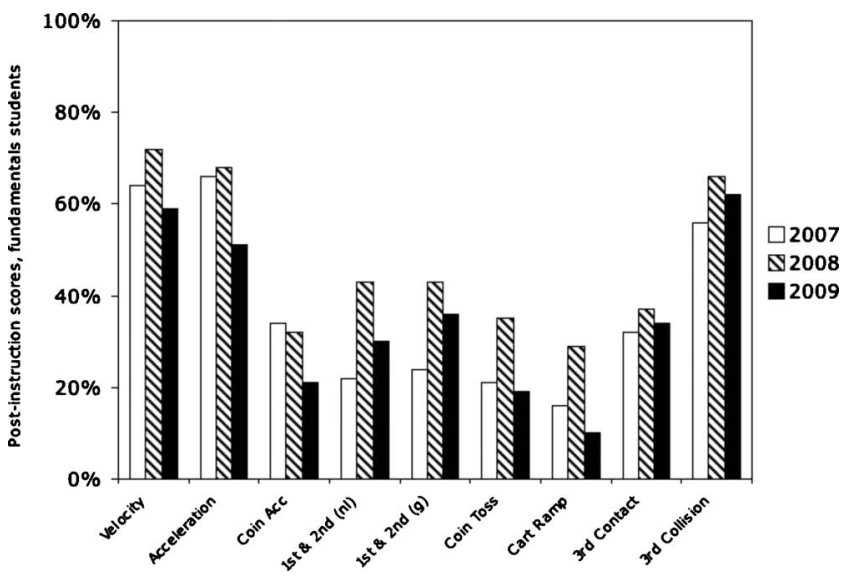

FIG. 6. Postinstruction scores for Fundamentals students, exposed to ILD methods of instruction, 2007-2009.

tioned earlier, it is never easy to coordinate well-defined experimental conditions in an education research project conducted in a large, busy university teaching department. So it cannot be stated unambiguously that the gains obtained were greater than would have been obtained in classes taught with traditional teaching.

Nevertheless there is much useful information to be obtained from analyzing the post-ILD results alone. In particular, paralleling the results of Project 1, it will be observed that the normalized gains vary from year to year in a characteristic way. In the first year, the gains are relatively low. They increase markedly in the second year when two of the lecturers were using ILDs for the second time, and one lecturer for the first. In the third year, two of the lecturers were on their third time, and the other lecturer on the second. We will speculate on the meaning of these observations below in the discussion section.

Lastly, we again compare our findings with those of other institutions. The average gains for each class are represented as points on a Hake plot as shown in Fig. 7.

\section{COMPARISON OF THE TWO PROJECTS}

The following observations can be made from the results of both projects 1 and 2 .

(i) Pretest scores do not vary drastically over the years (see Figs. 2 and 5). The students' level of conceptual understanding on enrolment stays much the same from year to year.

TABLE V. Average normalized gains for ILD teaching with Fundamentals students, for the three years, 2007-2009.

\begin{tabular}{ccccccc}
\hline \hline & & Preinstruction & $\begin{array}{c}\text { Standard } \\
\text { deviation } \\
(\%)\end{array}$ & $\begin{array}{c}\text { Postinstruction } \\
(\%)\end{array}$ & $\begin{array}{c}\text { Standard } \\
\text { deviation } \\
(\%)\end{array}$ & $\begin{array}{c}\text { Normalized } \\
\text { gains } \\
(\%)\end{array}$ \\
\hline 2007 & 90 & 13 & 11 & 40 & 24 & 31 \\
2008 & 115 & 18 & 14 & 53 & 28 & 42 \\
2009 & 158 & 17 & 13 & 40 & 23 & 28 \\
\hline \hline
\end{tabular}




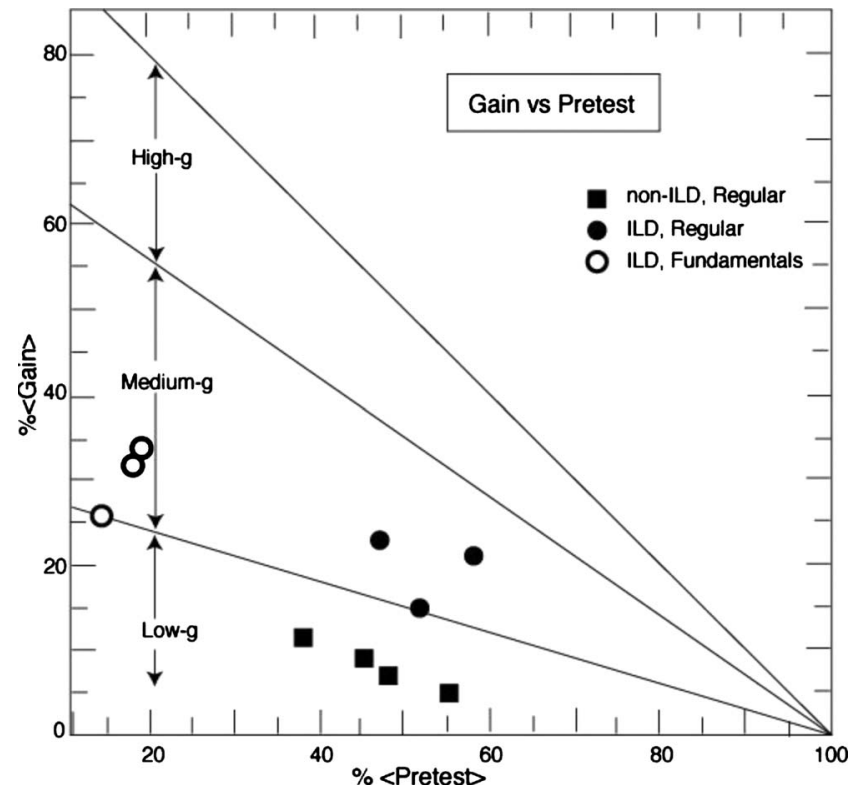

FIG. 7. Raw gains vs preinstruction scores for Fundamentals students, measured by the FMCE, 2007-9.

(ii) The relative gains made by students exposed to ILD methods of instruction are modest, considerably smaller than some claims made for them.

(iii) The relative gains made by students exposed to ILDs are remarkably similar, whether Regular or Fundamentals (Tables III and V). This seems to support the idea that teaching strategies which place emphasis on strengthening basic concepts can be useful at many different levels.

(iv) The relative gains vary from year to year. For both Regular and Fundamentals students the same pattern is found, which seems to depend on the experience of the lecturer with this kind of teaching. The second time he or she tries it achieves better results than the first time. There is even a suggestion that it falls again for the third time. This seems to give extra credence to the hypothesis, proposed at the end of Part 1, that the competence and enthusiasm of the instructor plays an important part. Any new course usually has teething troubles in its first year, which are smoothed out the second time through. On the third round the instructor may feel it should not need as much effort. An alternative explanation for the drop in year 3 (at least for Project 2), is that because of the marks incentive we were sampling a different group of students.

\section{TEACHER RESPONSES}

The results of the two Projects clearly show that, while the students exposed to ILD methods of instruction did make some gains, the gains are not spectacular. The question then arises, what were the experiences of the participating teachers? It is important to note that Project 2 was a research study underpinned by the intent to obtain useful data. Hence the teachers collaborated and held meetings resulting in a threeyear team teaching venture. Some of the teachers' experiences are extracted from the on-going discussions. To gain further insight each teacher provided a brief description of their experiences of using ILDs in their lectures.

Teacher 3 holds a research only position and has a keen interest in education. She teaches a couple of courses a year but this is not her core activity. She proposed and drove the use of ILDs in Project 2.

Voice of teacher 3: "The ILDs were a significant amount of work in the first year, when we were doing them for the first time. Running the experiments, and trying to stick as closely as possible to the scripted teacher-class interaction took far more time and effort than a corresponding traditional lecture would have done. The second time was indeed significantly easier, made even more so by the fact that from the second year (2008) we had a technician perform the actual experiments, leaving the teacher free to concentrate on the interaction with the class. As a teacher, it was initially difficult for me to stick closely to the format required for the ILDs-eliciting predictions, noting possible outcomes, then discussing the observed outcome-but the increased involvement of the class was certainly worthwhile. I did not feel any drop-off in effort in the third year; the fall in relative gain in the third year could be due to the fact that we had returns from a much higher proportion of the class, due to the marks incentive. A significantly higher number of students nominated the ILDs as the best part of the course in 2009 , compared to the earlier years."

Teacher 4 holds a teaching and research position and also coordinates the Intermediate (second year) Physics laboratory program. He has extensive university teaching experience across all years.

Voice of teacher 4: "I find that a compelling aspect of using the ILDs in teaching is their ability to engage the students in a way that is much harder to achieve in a "conventional" lecture. The students seem to appreciate the approach, as evidenced by the number of positive comments on the ILD sessions that turn up unsolicited in the feedback questionnaires which we invite students to complete at the end of each teaching module. In practical terms, the amount of preparation required prior to giving the ILDs for the first time was considerable, and juggling the performing of the demonstrations with the fairly ritualistic (but important, in my opinion) eight step interaction procedure with the students was challenging. For the second and third years I used ILDs I had the luxury of a technician being present to help with the demos themselves and this made things run smoother. I did find it a struggle to complete each Mechanics ILD to my satisfaction within the typically $50 \mathrm{~min}$ time span of a lecture, while following the recommended procedure. This may reflect on my individual lecturing style as much as anything. Certainly I find the ILD approach a useful tool and one which I am motivated to pursue further."

Teacher 5 is actively engaged in physics education research and as such she is familiar with the rationale and practices involved in this study. 
Voice of teacher 5: "I incorporate interactive strategies in my lectures via the use of classroom clickers and small group discussions. So the idea of using ILDs is not unusual. The clear advantage in using the ILDs is the strict structure and self-discipline I need to exercise. In retrospect, the number and spread of ILDs was appropriate for this course. It was a tremendous help when a technical staff ran the equipment while I focused on the class dynamics. In terms of professional development, the ILDs help operationalize what interactivity means and identify features that can be transferred to other teaching environments."

Teacher 6 is similar to teacher 3 , in that he is a researchfocused staff with a keen interest in education. After the first year of implementation (2007), he left to take a research only position at a different institution.

Voice of teacher 6: "The students were very responsive to the ILDs during the course, and verbal feedback from particular students indicated that at least some of them felt that they were developing stronger intuition regarding the concepts involved. Implementing the ILDs did require a moderate amount of training in advance, and the quality of the demonstrations certainly improved with practice. Clearly with more experience a lecturer can be more comfortable with the presentation to the class. The clarity of the presentation is critical, since a smooth presentation facilitates the interaction for the students without any interruption due to equipment or computer failures or technical difficulties, which distracts significantly from the process. It would be instructive to compare the relative gains from ILDs in comparison with other teaching methods involving demonstrations other than ILDs, to identify whether it is the ILD approach in particular, or simply any concrete demonstration that helps to clarify complex concepts."

Teacher 7 is similar to teachers 4 and 5. He has extensive teaching, coordination and curriculum design experience across all years of university physics education. Teacher 7 replaced teacher 6 in 2008 and 2009.

Voice of teacher 7: "I have twice given the part of the course which contains the first two ILDs. The ILDs made a very positive contribution-motion up and down an inclined plane may look simple to the eye, but it is not trivial to translate this into velocity vs time graphs, and the ILDs helped greatly. They provide variety and interest, and a good opportunity to build rapport between the class and the lecturer. The first one was too elementary for the class (students have no previous physics background, but many have a high entrance mark), but by the second ILD we had a good spread of correct and incorrect predictions. Student feedback always notes 'demonstrations' as one of the best things about lectures, but $20 \%$ of students specifically mentioned the ILDs, even though they were used in only 2 of 12 lectures. The effective delivery of the ILDs was greatly aided by having a lecture-demonstration staffer present to operate the computer data acquisition sys- tem, which enabled me to keep the focus on the physics questions."

In summary, merging the three-year team teaching experiences with what the teachers' have written, the ILDs were demanding to implement but considered worthwhile as a teaching and learning strategy. The following points can clearly be made:

(i) The use of ILDs led to increased involvement of the class.

(ii) The ILDs changed the class dynamics providing $a$ good opportunity to build rapport between the class and the lecturer.

(iii) The ILDs were popular with the students who specifically mentioned the ILDs, even though they were used in only 5 of 25 lectures.

(iv) Some students felt that they were developing stronger intuition regarding the concepts involved.

(v) What was supposed to happen during each class was well defined and for a teacher, it was initially difficult to stick closely to the format required for the ILDs.

(vi) The ILDs need to proceed without any interruption due to equipment or computer failures or technical difficulties.

(vii) The effective delivery of the ILDs was greatly aided by having a lecture-demonstration staffer present to operate the computer data acquisition system.

Considerable effort is required in delivering the ILDs, particularly in the first year. We note that at this department, a fairly sophisticated support system for lecture demonstrations is available. The teacher simply requests ILDs, and inspects the setup prior to the lecture. Teachers do not set up the ILD by themselves. In 2008 and 2009, the technical support person carried out the demonstrations while the teacher choreographed the interactions. Situational factors such as these have been found to be important in the uptake of research based instructional methods [19].

\section{CONCLUSIONS}

One of the main motivations behind this project, at least initially, was to see if the use of ILDs in an Australian context would yield results similar to those reported by the originators of this teaching strategy. The finding was as reported above. The context was different, so it should not be surprising that the results were not the same. Perhaps the experiment conducted in Sydney was a more realistic assessment of the ILD approach. Perhaps it was just different. Nevertheless our results leave no doubt that the ILD teaching strategy can make a valuable contribution to student learning and teacher professional development.

At the same time, our study demonstrates that there are difficulties for implementation-such as the need for technical support staff and the additional time required at the beginning, for training and initial implementation. This should not be overstressed. There are numerous examples of ILDs being carried out by a single dedicated teacher, but ILDs are very heavily dependent on equipment and it is easy to see that, for busy lecturers in large teaching departments, such difficulties could prove overwhelming-which surely an- 
swers the question posed at the beginning of this paper: Why do not more physics courses use interactive engagement strategies?

Nonetheless we are aware that more and more teachers are taking note of such strategies and their potential benefits. So we live in the hope that, one day, it will no longer be accepted that traditional, chalk-and-talk teaching is still the norm.

\section{ACKNOWLEDGMENTS}

The authors would like to thank the lecture demonstration staff, students and members of the Sydney University Physics Education Research group who have assisted in various ways throughout this project. We extend our thanks to the Reviewers for their insightful comments.
[1] C. Wieman and K. Perkins, Transforming Physics Education, Phys. Today 58(11), 36 (2005).

[2] D. A. Muller, M. D. Sharma, and P. Reimann, Raising cognitive load with linear multimedia to promote conceptual change, Sci. Educ. 92, 278 (2008).

[3] R. Duit and D. F. Treagust, in International Handbook of Science Education, edited by B. J. Fraser and K. G. Tobin (Kluwer Academic Press, Dordrecht, The Netherlands, 1998), pp. $3-25$.

[4] S. Wuttiprom, M. D. Sharma, I. D. Johnston, R. Chitaree, and C. Soankwan, Development and use of a conceptual survey in introductory quantum physics, Int. J. Sci. Educ. 31, 631 (2009).

[5] L. Ding, R. Chabay, B. Sherwood, and R. Beichner, Evaluating an electricity and magnetism assessment tool: Brief electricity and magnetism assessment, Phys. Rev. ST Phys. Educ. Res. 2, 010105 (2006).

[6] K. Cummings, J. Marx, R. K. Thornton, and D. E. Kuhl, Evaluating innovation in studio physics, Am. J. Phys. 67, S38 (1999)

[7] L. C. McDermott, P. S. Schaffer, and the Physics Education Group, Tutorials in Introductory Physics (Prentice-Hall, Upper Saddle River, 1998).

[8] FLAG, http://www.flaguide.org/cat/diagnostic/diagnostic1.php

[9] R. R. Hake, Interactive-engagement versus traditional methods: A six-thousand student survey of mechanics test data for introductory physics courses, Am. J. Phys. 66, 64 (1998).

[10] D. R. Sokoloff and R. K. Thornton, Using Interactive Lecture Demonstrations to Create an Active Learning Environment,
Phys. Teach. 35, 340 (1997).

[11] R. K. Thornton and D. R. Sokoloff, Learning motion concepts using real-time microcomputer-based laboratory tools, Am. J. Phys. 58, 858 (1990).

[12] R. K. Thornton and D. Sokoloff, Assessing student learning of Newton's laws: The Force and Motion Conceptual Evaluation and the evaluation of active learning laboratory and lecture curricula, Am. J. Phys. 66, 338 (1998).

[13] S. Ramlo, Validity and Reliably of the Force and Motion Conceptual Evaluation, Am. J. Phys. 76, 882 (2008).

[14] T. I. Smith and M. C. Wittmann, Applying a resources framework to analysis of the Force and Motion Conceptual Evaluation, Phys. Rev. ST Phys. Educ. Res. 4, 020101 (2008).

[15] R. K. Thornton, D. Kuhl, K. Cummings, and J. Marx, Comparing the force and motion conceptual evaluation and the force concept inventory, Phys. Rev. ST Phys. Educ. Res. 5, 010105 (2009).

[16] D. R. Sokoloff and R. K. Thornton, in Introductory Physics, The Physics Suite (John Wiley \& Sons, Inc, Hoboken, NJ, 2004).

[17] D. Halliday, R. Resnick, and J. Walker, Fundamentals of Physics, 6th ed. (John Wiley and Sons, New York, 2001).

[18] D. Hestenes, M. Wells, and G. Swackhamer, Force concept inventory, Phys. Teach. 30, 141 (1992).

[19] C. Henderson and M. H. Dancy, Barriers to the use of research-based instructional strategies: The influence of both individual and situational characteristics, Phys. Rev. ST Phys. Educ. Res. 3, 020102 (2007). 